\title{
COMPARATIVE EFFECTS OF TRANSCUTANEOUS ELECTRICAL NERVE STIMULATION, CRYOTHERAPY AND PLACEBO ON PAIN, SWELLING AND TRISMUS FOLLOWING THIRD MOLAR TOOTH EXTRACTION
}

\author{
Journal website at; \\ http://mrtbjournal.org/index.php/njmr/issue/current/showToc \\ ${ }^{1}$ MOB OLAOGUN, ${ }^{2}$ GE PARKINS, ${ }^{2}$ MO BOAMA, ${ }^{1}$ ER ADDO, ${ }^{2} \mathrm{D}$ AVOGO, ${ }^{1} \mathrm{~K}$ APPIAH-KUBI \\ ${ }^{I}$ Department of Physiotherapy School of Allied Health Sciences (SAHS) College of Health Sciences \\ (CHS) University of Ghana \\ ${ }^{2}$ Department of Oral and Maxillofacial Surgery Dental School, CHS, University of Ghana
}

\author{
Correspondence to: \\ Matthew OB Olaogun \\ Department of Medical Rehabilitation College of Health Sciences \\ Obafemi Awolowo University, Ile Ife, Nigeria \\ mobolaogun@yahoo.co.uk \\ Mobile: +2348037260562
}

\section{SUMMARY}

Background \& Objective: This study compared the therapeutic effects of Transcutaneous Electrical Nerve Stimulation (TENS), Cryotherapy and Placebo on pain, swelling and trismus following surgical extraction of the third molar tooth.

Methods: Eighteen (18) patients who underwent surgical extraction of the impacted tooth were randomly assigned into three groups- TENS, Cryotherapy and Placebo. Following the surgery, a standard form of TENS was applied over the painful area of cheek for TENS group, Ice was applied directly over the painful area for Cryotherapy group. The TENS machine was detuned while electrodes were applied on the painful sides of the cheek for Placebo group. The pre-operative, pre and post physiotherapy treatment pain ratings, swelling and mouth opening were monitored in each group and the results were compared. Data were analyzed with ANOVA, Turkey's Post-Hoc and t-tests. Level of significance used was 0.05 .

Results: There was significant reduction in pain in all the groups. TENS and Cryotherapy were more effective in pain modulation than Placebo treatment. Significant reduction in trismus was also demonstrated in the TENS and Cryotherapy over the placebo group $(\mathrm{P}<0.05)$. Apart from the placebo treatment, the result did not show significant changes $(p>0.05)$ in swelling resolution.

Conclusion: TENS and Cryotherapy were more effective than Placebo treatment in pain modulation and relief of trismus following dental surgery. Therefore the choice between TENS and Cryotherapy should be based on availability and easy accessibility. Further studies with larger number of patients are suggested to evaluate the effect on swelling resolution.

Key words: TENS, Cryotherapy, Placebo, Pain, Swelling, Trismus.

\section{INTRODUCTION}

TENS is a form of electrical stimulation frequently used by physiotherapists as a pain relieving modality. Several studies have investigated its efficiency in pain relief (Thorsteinsson et al, 1978; Walsh et al, 1990; Olaogun et al, 2001). TENS provides a degree of pain relief by specifically exciting sensory nerves- stimulating the large diameter $\mathrm{A}$-alpha and $\mathrm{C}$ fibres. There are theories that have been proposed to explain how pain could be altered by electrical stimulation; such include the pain gate (Melzack and Wall, 1965), endorphin release proposed by Sjolund and Erickson (1979) and post excitation depression of the sympathetic nervous system proposed by Sato and Schmidt (1973).

Cryotherapy is the application of ice for the treatment or management of injuries, diseases and pain. It can be applied in forms of ice packs, ice shushes, vapocoolant sprays or chilled whirlpools. Its physiological effects include analgesia, vasoconstriction and control of swelling (Kitchen, 2002). Cryotherapy can stabilize the membrane and reduce cell metabolism leading to a local reduction in pain (Lee et al, 1978).

Placebo is defined as any therapy or component of therapy that is deliberately used for its nonspecific, psychological, or psychophysiological effect. A percentage of people respond to placebo treatment (Thonsteinson et 
al, 1978).

Third molar extraction is usually done as a day case under local anesthesia, the effect blocks feeling in the jaw and gum and patient stays awake throughout the period of the operation. The dental surgeon cuts through the gum and may remove some of the jawbone to reach the tooth which is then removed and the wound is closed with stitches (Weil et al, 2007).

The possible sequelae of this surgical procedure are pain, swelling and trismus. Others include hemorrhage, alveolar osteitis, soft tissue infection, temporary paraeathesia and permanent anesthesia and numbness of the lips, tongue and cheek. The numbness is due to injury to the mandibular and lingual nerves. (Student's Microsoft Encarta, 2008).

Pain , according to the International Association for the Study of Pain (IASP), is an unpleasant and emotional experience associated with actual or potential tissue damage or described in such terms (Readyard and Edwards, 1992). Pain is a result of inflammation, the tissue response to the surgical injury and is produced by the release of chemical mediators such as histamine and bradykinin.

Swelling is a result of increase in vascular permeability during the acute inflammation process. Protein-rich fluid escapes from the blood stream into the tissues and accumulates in the interstitial spaces in order to bathe the surgically injured area with increased amount of nutrients and disease fighting constituents of the blood. However, the pressure of the inflammatory exudates on the sensory nerve endings of the teeth also increases the patient's perception of pain (Kumar et al, 2006).

Trismus, a restriction in mandibular opening, may be due to spasm of the masseter muscles. It is the same symptom which is often the initial manifestation of generalized tetanus (lock jaw) (Starke, 1997). Medically, patients are often placed on antibiotics to combat infection and analgesics to modulate the post-surgical pain.

The purpose of this study is to compare the therapeutic effects conventional TENS and Cryotherapy on pain, swelling and trismus following third molar tooth extraction.

\section{MATERIALSANDMETHODS \\ Study Site}

Oral and Maxillofacial Surgery Clinic of the University of Ghana Dental School, and the Physiotherapy Department of Korle-Bu Teaching Hospital, Accra, Ghana.

\section{Study Sample}

Eighteen (18) patients who underwent surgical extraction of impacted third molar teeth were randomly assigned into three groups- TENS, Cryotherapy and Placebo.

\section{Ethical Issues}

Patients were given explanation on an informed consent sheet in respect of the study. Verbal participation and written informed consents were obtained from participants. Patients were on the prescribed antibiotics after the surgical extraction and were advised not to take any analgesic but could only do so if there was a need. Ethical clearance was obtained from the Ethical Review Committee of the School of Allied Health Sciences.

\section{Instrumentation}

An EV-507D Combo Stim Digital TENS/EMS (Mucha, Taipei, ROC) machine was used to administer TENS to those in the TENS groups in this study.

VISUALANALOGUE SCALE (VAS), a self report by patient was used to rate pain intensity. It is a $10 \mathrm{~cm}$ horizontal line with mark of zero and ten at the two ends signifying no pain and worst pain respectively.

PAIR OF DIVIDER was used together with a short rule to measure the interincisal distance pre and post extraction of the tooth.

An inextensible MEASURING TAPE (Singer, China) was used to measure the linear distance from the anatomical land mark of the mastoid bone to mandibular mid line to assess oro-facial swelling in centimeters.

ICE CUBES of appropriate size were used for Cryotherapy.

\section{Procedure \\ PRE-OPERATIVEEXAMINATION}

Each patient was initially assessed for mouth opening with the pair of divider and a ten centimeter rule following the procedure of Okeson (1993).

\section{POSTOPERATIVEATTENTION}

The following were recorded immediately after the operation: duration surgical extraction and patient's pain level. Cheek swelling was measured with the tape measure following the procedure of Killey and Kay (1980). Patients were treated with TENS and cryotherapy based on the group assigned on the first day and then referred to Physiotherapy Department for further assessment and treatment on subsequent days. All the patients were given antibiotics and no analgesics.

TENS participants were treated with TENS (frequency of $50 \mathrm{HZ}$, short pulse duration of 100 microseconds) for 15 minutes.

For Cryotherapy participants; block of ice was applied (and rubbed) directly on the painful part of the cheek for 15 minutes daily.

Placebo participants had the electrodes fixed in place with the TENS machine detuned, for 15 minutes. Each participant was treated daily and followed-up for six days, that is each participant had six (6) treatment sessions. The study lasted approximately ten (10) weeks.

\section{Data Analysis}

Relevant data collected in the study were analyzed using descriptive statistics of means and standard deviations. T-test was used for pair wise comparison of pretreatment (1st Day-Postoperative) and post treatment (6th Day- 
Postoperative) mean values of variables in each group. Analysis of variance (ANOVA) was used to compare the means of post-treatment pain ratings, swelling and mouth openings across the three groups. Turkey's post-hoc comparison was performed to determine which pairs of means showed significant differences between TENS and Cryotherapy, TENS and Placebo and Cryotherapy and Placebo treatments, on the first and on the sixth day postoperatively. Alpha level of 0.05 was used for this study.

\section{RESULTS}

Table 1 summarizes the distribution of the participants' ages and durations of surgical extraction.. None of the patients reported the use either of any analgesic or of any drug outside the prescribed antibiotics. Figures 1,2 and 3 are comparative graphs of the overall changes (between Day 1 and Day 6) in the variables monitored pain intensity, swelling resolution and trismus relief (measured by mouth opening). TENS and Cryotherapy were shown to be more effective in pain modulation and trismus relief than the Placebo.

With reference to Table 2, there was significant reduction in pain intensities in all the three groups $(\mathrm{p}<0.05)$. There was no significant reduction in swelling in the TENS and Cryotherapy groups $(p>0.05)$, but the Placebo treatment presented a significant effect in swelling resolution $(p<0.05)$. There was significant improvement in mouth opening in the TENS and Cryotherapy groups. The placebo treatment did not present significant effect in trismus resolution $(\mathrm{p}>0.05)$.

Table 3 is the result of ANOVA of post treatment pain rating, swelling and trismus values of the 3 groups. There was significant difference $(\mathrm{P}<0.05)$ across the three groups amongst the variables. Table 4 is the result of Turkey's posthoc analysis sequel to above. It was revealed that TENS and Cryotherapy were significantly more effective in pain modulation than the placebo $(\mathrm{p}<.05)$, but no significant difference was found between the TENS and Cryotherapy groups ( $\mathrm{P}<0.05)$. On trismus, post-hoc analysis revealed that Cryotherapy was significantly more effective than either TENS or Placebo; there was no significance difference between TENS and Placebo $(p>0.05)$ in trismus resolution. The mean absolute values of post treatment orofacial measurements are considered for swelling. There were significantly higher values in Placebo than Cryotherapy and in Cryotherapy than in TENS ( $p<0.05$ ). (Significantly higher value does not mean significantly greater effect of treatment here). Table 2 shows the significant effect of Placebo in swelling resolution.
Table 1: Summary of age of patients and duration of surgical extraction.

\begin{tabular}{|c|c|c|c|}
\hline Variables & $\begin{array}{l}\text { TENS GROUP } \\
(\mathrm{n}=6)\end{array}$ & $\begin{array}{l}\text { PLACEBO } \\
\text { GROUP } \\
(\mathrm{n}=6)\end{array}$ & $\begin{array}{l}\text { Cryotherapy } \\
(\mathrm{n}=6)\end{array}$ \\
\hline D: & Mean + & $1+5$ & Mean + SD \\
\hline Age & $28.72 \quad 4.1$ & 2.02 & $28.00 \quad 3.09$ \\
\hline Duration of & $34.17 \quad 9.48$ & $36.33 \quad 8.56$ & $40.72 \quad 8.22$ \\
\hline
\end{tabular}

Extraction (Minutes)

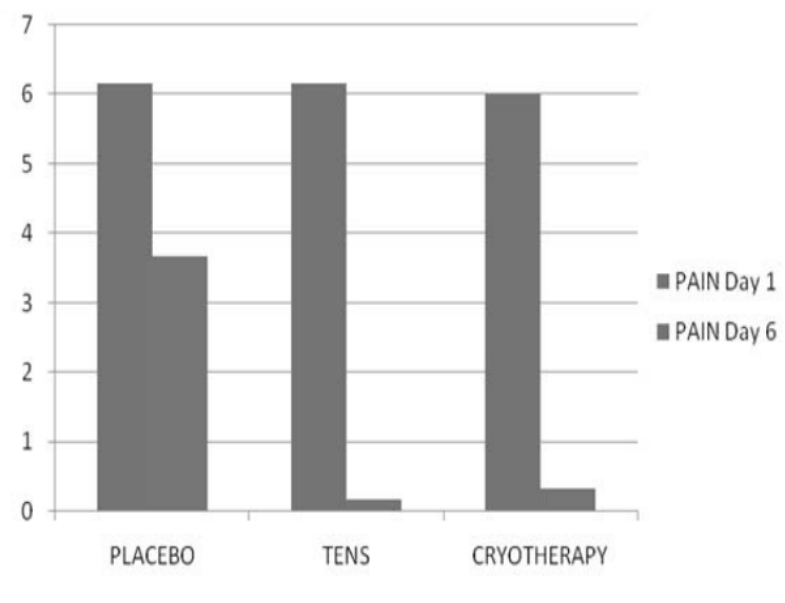

Fig. 1: Bar chart showing the effects of the Placebo, TENS and

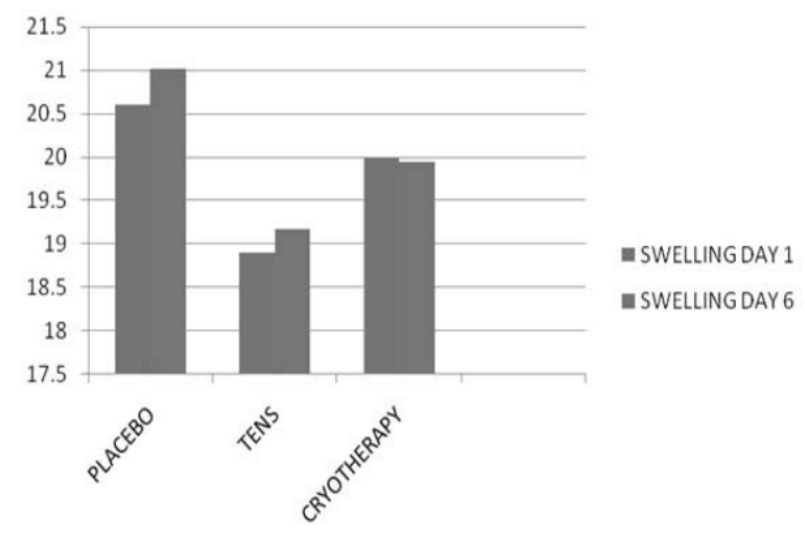

Fig. 2: Bar chart showing the effects of the Placebo, TENS and Cryotherapy on the swelling resolution (measures in centimeters) of patients from the beginning till the end of treatment 


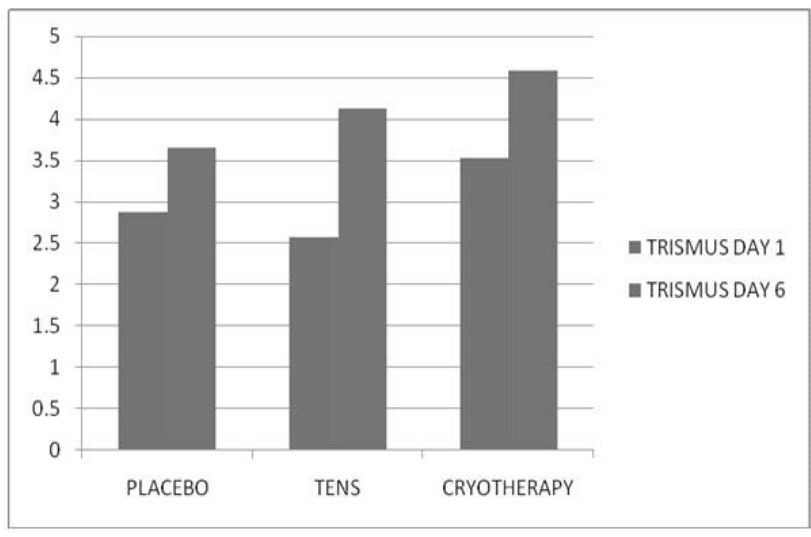

Fig. 3: Bar chart showing the effects of the Placebo, TENS and Cryotherapy on the range of mouth opening (interincisal distance in centimeters) of patients from the beginning to the end

Table 2: Paired t-test Comparing pre (Day 1) and post (Day 6) treatment variables per each modality TENS, Placebo, and Cryotherapy.

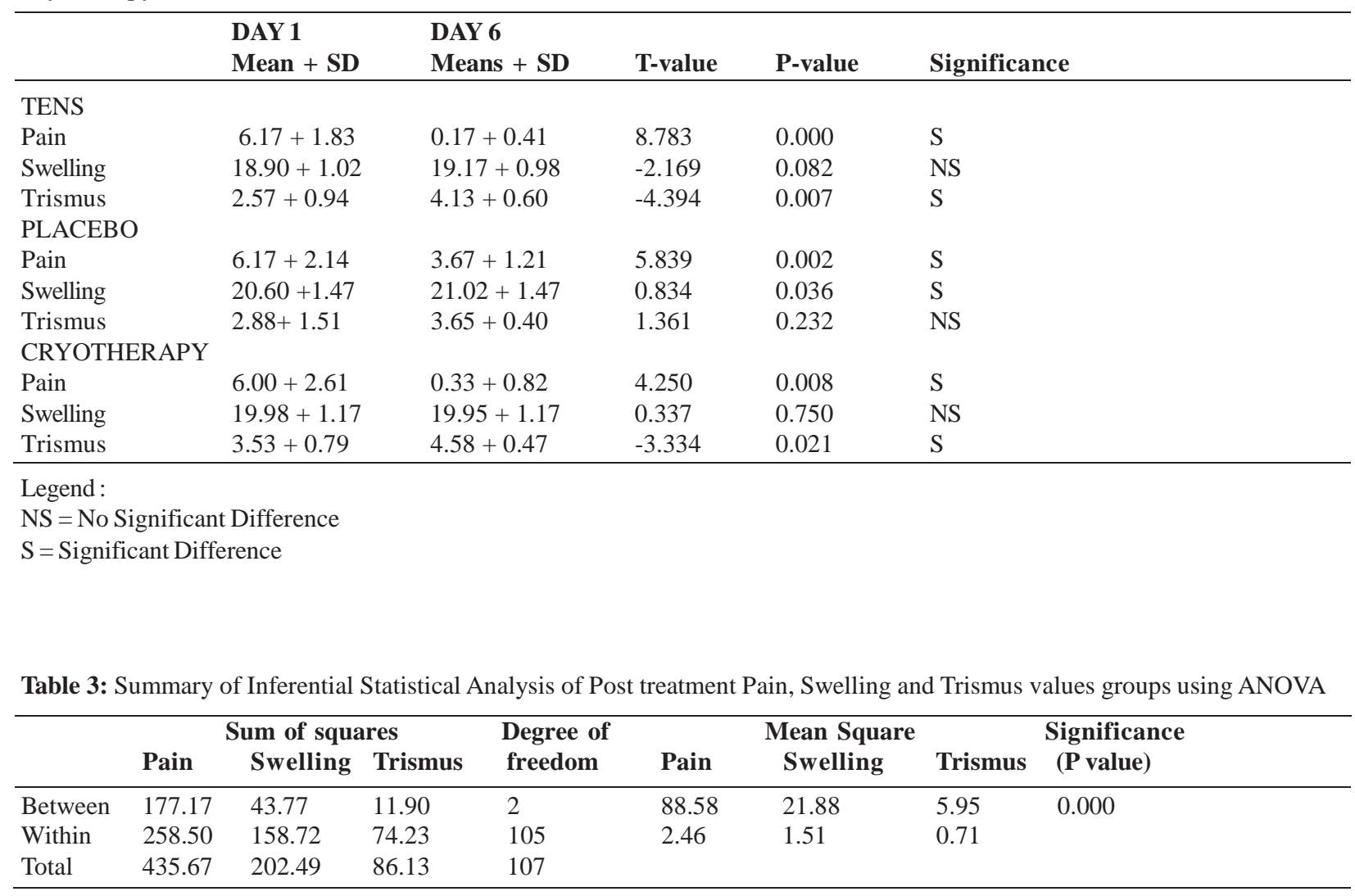

Table 4: Summary of Turkey's Post-Hoc analysis of Post treatment Pain, Swelling and Trismus values.

\begin{tabular}{llllllllll}
\hline Group-Group & \multicolumn{3}{c}{ Mean difference } & \multicolumn{3}{c}{ (P value) } & \multicolumn{3}{c}{ Significance } \\
& Pain & Swelling & Trismus & Pain & Swelling Trismus & Pain & Swelling & Trismus \\
\hline Placebo-TENS & 2.58 & 1.55 & -0.31 & 0.000 & 0.000 & 0.123 & S & S & NS \\
Placebo-Cryotherapy & 2.88 & 0.90 & -0.81 & 0.000 & 0.002 & 0.000 & S & S & S \\
Cryotherapy-TENS & -0.25 & 0.65 & 0.50 & 0.501 & 0.026 & 0.014 & NS & S & S \\
\hline
\end{tabular}




\section{DISCUSSION}

This study showed that TENS, Cryotherapy and Placebo treatment were effective in relieving pain secondary to third molar tooth extraction. This study finding on TENS supported the study by Strassburg et al (1977) on the influence of TENS on acute pain. They reported that 29 of their 30 patients underwent tooth extraction without additional anesthesia when TENS was applied over the trigeminal nerve at its exit through the mandible. In another study on the effects of TENS on pain, swelling and trismus following dental extraction , Olaogun et al (2001) found TENS to be more effective than placebo in pain modulation.

The possible mechanism by which TENS relieves pain has been attributed to its inhibitory effect on gelatinosa interneuron by closing the gate to transmission of nociceptive information (Melzack and Wall, 1965). Belanger (1985) postulated that TENS analgesic effect was also partially modulated by endogenous opiate relatedpain modulating system in the brain. Thonsteinson el al (1978) evaluated the placebo response to TENS treatment. They found that placebo analgesic effect occurred in $32 \%$ of trials as compared to genuine electrical stimulation. The significant reduction in pain in the Placebo group in our study, therefore, may be attributed to actual neurophysiologic events mediated through cognitive, emotional and attitudinal changes, raising the level of pain threshold and pain tolerance.

Pain modulation by the Cryotherapy can be attributed to its physiological effects which include analgesia, vasoconstriction and control of swelling (Johnson, 2000). Thermo receptors in the skin are stimulated and produce an autonomic reflex vasoconstriction over the painful surface. Ice cooling lowers the local temperature, reduces cell metabolism and the rate of firing of the nociceptors, leading to a local reduction in pain (Kitchen, 2002). Analgesic effect of cold application can also be explained on the basis of pain gate theory and mediation through the roles of morphine receptors in the CNS and the encephalin and endorphins (Doubell, Mannon and Wolf, 1999).

This study revealed that neither TENS nor Cryotherapy demonstrated any significant effect in swelling resolution $(\mathrm{p}>0.05)$. This finding on Cryotherapy is in contrast to empirical evidence that the use of ice reduces swelling in acute injury (Basur et al, 1976). There was significant resolution in swelling in the placebo group. The apparent ineffectiveness of TENS and Cryotherapy over the placebo, on swelling, in this study cannot be explained. But the following reasons may be offered: : the conventional TENS used in the study was not strong enough to produce muscle contraction that will aid venous return; the period of study was fixed (6 days) for each participant, whereas rate of swelling resolution might vary even within the group; according to Kitchen (2002), in clinical practice Cryotherapy is often accompanied by compression, swelling reduction may therefore not be ascribed to cooling alone. Compression could not be employed in this study. Further studies with larger samples of participants, with longer period of study and with the use of acupuncture like TENS, with motoric functionsproducing slow rhythmic muscle contractions are suggested.

TENS and Cryotherapy demonstrated significant effect on trismus (Table 2). However, Cryotherapy was significantly more effective than either TENS or Placebo ( $\mathrm{p}=0.014 ; \mathrm{p}=0.000$, respectively), but there was no significant difference between TENS and Placebo $(\mathrm{p}=0.123)$ in trismus resolution (Table 4). Trismus is a protective spasm of the muscle of mastication, particularly the masseter muscle, restricting the mandibular opening. Pain modulation by TENS and Cryotherapy coupled with the anti-inflammatory influence of the prescribed antibiotics might have attenuated the spasm.

\section{CONCLUSION}

The results of this study supported previous studies on the analgesic effect of TENS, Placebo treatment and Cryotherapy. Furthermore, the study revealed that TENS and Cryotherapy were also effective in relieving trismus following dental surgery. Further studies are suggested to evaluate the effect of these modalities in swelling resolution.

\section{REFERENCES}

- Basur R, Sherpherd E Moses G (1976) A cooling method in treatment of ankle sprain. Practitioner, 216: 708

- Belanger AY (1985) Physiological evidence for an endogenous opiate-related pain modulating system and it relevance to TENS: A review of literature. Physiotherapy Canada. 37: 1080-4.

- Doubell P, Mannon J, Woolf CJ (1999) The dorsal horn: State dependent sensory processing, plasticity and the generation of pain in Wall PD, Melzack R [eds] Textbook of Pain 4th edn Churchill Livinstone, New York 165-182.

- Killey HC, Kay LY. (1980) The impacted wisdom tooth. Churchill Livingstone Inc. pp.112-118.

- Kitchen S (2002) Heat and Cold: Conduction methods in Kitchen S [ed] Electrotherapy: -Based Practice. Churchill Livingstone 129-136.

- Knight KL. (1995) Cryotherapy in sports injury management. Champaign IL: Human Kinetics pp: 3-98.

- Kumar V, Mitchel RN, Abbas AK, Fausto N (1996) Pathologic basis of diseases, Saunder, Philadelphia 44-46.

- Lee JM, Warren MP, Mson SM. (1978). Effects of Ice the on nerve conduction velocity. Physiotherapy, 64: 2-6.

- Melzack R Wall PD (1965) Pain Mechanism: A new theory. Science. 150: $971-979$

- Melzack R, Wall PD (1996) The Challenge of Pain [2nd 
edn]. Penguin, London

- Okeson JP (1993) Management of temporomandibular joint disorders and occlusion. Mosby Year Book Inc. [3rd Edition]

- Olaogun MOB, Fagade OO, Akinloye AA, Omojowolo O (2001) Effects of Transcutaneous Electrical Nerve Stimulation on pain, swelling and trismus following third molar tooth extraction. Nigerian journal of Health Sciences, 1 (1): $18-22$

- Readyard LB, Edward WT (1992) Management of Acute Pain: A practical guide. International Association for the Study of Pain Publication, Seattle,

- Sato A, Schmidt RF (1973) Somatosympathetic Reflexes: Afferent fibres, central pathways, discharge characteristics. Physiological Reviews, 53(4): 916-947.

- Sjolund BH, Erickson MBE. (1979) Endorphins and Analgesia produced by peripheral conditioning stimulation. Advances in pain research and therapy, Vol 3.

- Starkes RD. (1997) The Merck Manual of Medical Information. Pocket Books, New York
- Strassburg HM, Kranic JV, Thoden V (1977) Influence of TENS on acute pain. Journal of Neurology, 217: 1-10

- Students Microsoft Encarta. Third molar tooth. Available from: http// www.encarta.msn.com/text 761562931 14/ teeth.html.

- Thorsteinsson G, Stonnington HA (1978) The placebo effect of transcutaneous electrical stimulation. Pain, 5: 31-41.

- Walsh ME, Martin BC, Deyo RA (1990). A controlled trial of transcutaneous electrical nerve stimulation and exercise for chronic low back pain. $N$ England Med: 322: $1647-$ 1634.

- Weil K, Hopper L, Afzal Z, Esposito AM, Worthington HV, Wijk AJ, Coulthard P. (2007) Paracetamol for pain relief after surgical removal of lower wisdom teeth. Cochrane Databases of Systematic Reviews, 3.

- Wells G, Milne S, Welch V, Brosseau L, Saginum M, Shea B, Tugwell P. (2001). TENS for chronic Low back Pain (Cochrane Review). In: The Cochrane Library 4, Oxford: Updated software. 